\title{
IJTARP
}

\section{Autonomy or Dependence: Working with Therapeutic Symbiosis in the Non-Psychotic Therapist-Client Relationship}

\author{
(C) 2018 Vitor A Merhy
}

This paper appeared originally in Portuguese as Crescendo em direção à autonomia ou à dependência? - Trabalhando a simbiose na relação terapeuta-paciente não psicótico REBAT XXII August 2013 9-34 and is reproduced here by kind permission of UNAT-BRASIL - União Nacional de Analistas Transacionais - Brasil.

\begin{abstract}
Symbiosis is a concept developed by Schiff and others in her work with clients with severe psychoses such as schizophrenia. It is our intention with this article to propose a reflection on its applicability with our nonpsychotic clients, within the practice of consultation. By reviewing the theory of development, by authors with a theoretical framework of transactional analysis, we seek to establish the possibilities of what can happen within the primary symbiosis through its nonresolution, within each period of development of the human being from conception to the adult phase. In this primary symbiosis, when unresolved, the establishment of script and the matrix of the various relationships of dependence in life will be developed. Resolution of this through therapeutic symbiosis in the therapist-client relationship may lead to attainment of Berne's autonomy with its components of awareness, spontaneity and intimacy.
\end{abstract}

\section{Keywords}

Transactional Analysis; Symbiosis; Developmental Theory; Autonomy; Dependency Relationship

\section{Introduction}

Dependency relationships permeate the interactions between elements, in the universe, in the solar system and in nature. Many species depend on each other for their survival, and this occurs in a similar way in the human species. Initially, there is an energetic and physiological dependence and, with growth, also a psychological one. And this is the cause, if not resolved, of relationships of dependence that last a lifetime.

Every structure of the human personality is developed within an initial symbiotic relationship towards autonomy, the natural and ultimate goal of growth. It is our purpose, when making a theoretical approach, from the point of view of transactional analysis (TA), to evaluate in which moments of biophysiological development, our autonomy is gradually replaced by the construction of a dependency and leads us to establish relationships through the rest of our lifetime that are similar to the matrix of the initial relationshipship with our mother [or other primary caregiver].

Schiff (1986) focused her work on symbiosis when dealing with serious psychopathologies. By stating that "every meaningful relationship will have, at some time, an element of symbiosis," (p. 5) she provides support for her studies to be adapted to the milder psychopathologies found in day-to-day practices.

An analysis of the symbiotic events occurring during the developmental stages will allow us to process therapeutic intervention in the therapist-client relationship during the course of the therapy process. To better understand this, we will take a theoretical tour - our emphasis - through the stages of development of the human being identifying relationships between the phases of establishment of the primary symbiosis and the possibilities that may have occurred by making it a fixed gestalt.

Many authors have addressed the theme of developmental stages, including Freud, Piaget, Spitz, Erikson, Spock, Gesell, and Winnicott among others; we will remain, however, with those who did it under the theoretical framework of TA: Berne $(1977,1988)$, Schiff (1986), English (1977), Levin-Landheer (2010), Kertész (1985) and Del Casale (1986). 


\section{Autonomy as a goal}

To be autonomous, it is necessary to acquire the possibility of governing oneself, determining one's destiny, taking responsibility for one's actions and feelings, discarding inadequate beliefs and values in order to live in the here-and-now with emancipation and independence. Within the concepts of TA "the attainment of autonomy is manifested by the liberation or recovery of three capacities: awareness, spontaneity and intimacy." (Berne, 1977, p.155)

To be aware is to have the knowledge of what is happening here-and-now, to perceive the world through your own contact with it instead of seeing it as it has been taught, to be present and consonant with your body, thoughts and emotions. "The conscious person is alive because he knows what he feels, where he is and the moment he lives." (Berne, 1977, p.157)

To have spontaneity is to have behaviours that flow naturally and easily, to be timely, to be able to change effortlessly according to the demands and needs of each moment, to have an integrated response, to be flexible, responsible for our choices and to make our own decisions. It should not be confused with doing anything anytime, anywhere, anyways. To have spontaneity, for Berne (1977), "means being freed from the compulsion to have only the feelings one has learned to have." (p.157)

To be in intimacy is to be connected with feelings of affection to people in a relationship, be it emotional, physical, intellectual or even spiritual. It is to be able to express feelings of warmth and tenderness, to be able to contact other people and to let oneself be contacted by them in a natural way, with proximity making each encounter a unique and satisfying experience.

\section{Symbiosis as a way}

From our conception, we begin our existence within a relationship of dependence. A relationship of dependence with our great first love, our Mother. (sic) Popular wisdom says that Mother is like chickenpox. Have it once and it will leave a mark forever - our emphasis -. The simplicity of this phrase translates and contains the strength and importance of our first love relationship, which will shape all our affective relationships.

In TA we call a symbiosis a relationship of dependence that is what "occurs when two or more individuals behave as though between them they form a whole person" (Schiff, 1986, p. 5). Schiff further clarifies that symbiosis is a natural occurrence between parents and children until they can live on their own and this primary symbiosis becomes pathological when it interferes with the development of autonomy when we reach adulthood.
In this unresolved or pathological relationship of symbiosis, according to Schiff, we must take into account three important aspects that maintain and justify it: non-productive or passive behavior, discounting and grandiosity.

In pathological symbiosis two positions can be occupied: either the person will put themself in a position where another will take care of them and the problems become the caregiver's and must be solved by the caregiver, or the person will put themself in the role of taking care of the other, who is then the owner or the cause of the problems and cannot live without the caregiver to solve them.

Thus, the resolution of symbiosis, whether natural or pathological, is the way to achieve autonomy.

\section{Before birth}

Primary symbiosis, which is fundamental in the development of the human being, begins with conception, when the couple prepares to have a child, and continues throughout the gestation until birth, lasting until the end of adolescence, when it should be resolved.

In this first phase, if conception is desired and performed with love, the mother-child bond begins to be constructed in a positive way. The result may be quite different if the conception is the result of a relationship occurring by chance or rape and aggression.

Throughout the gestation the baby, in visceral contact with the mother, will be receiving vibrations from the mother as well as all her biochemical production. The baby will receive, from the context within which the parents function, positive influences within a healthy emotional environment or negative from an emotionally rejecting environment in an unwanted pregnancy. In this period, there will also be expectations about the child, such as what gender it will be, choice of name or the role it will play in the life of the parents.

As the primary symbiosis begins to establish itself between the mother and the baby, there is also a symbiosis, of support, between the father and the mother. This is the ideal setting for gestation. In contrast, abortion attempts as well as stress or serious maternal illness can occur during gestation and will shape an unfavorable environment for the establishment of primary symbiosis.

Often an intense disqualification of the needs of the parental Child ego state will also provide an early establishment of unhealthy primary symbiosis, as it will develop within an ambivalent environment of love and anger, being a product of the resentment of the Child ego state of the parents. 


\section{The first months}

Healthy primary symbiosis, established physiologically during gestation, at birth organizes, supports, and is complemented by the onset of the parenting process of the child. This is necessary and fundamental since the child is born only with the Child ego state - C1- or natural, active Child. In this first stage begins the primary neuropsychophysiological organization that gives the bases and the structure for the formation of the personality. The discovery of one's own existence occurs and the baby learns "that there is a part of the world which they are and part which they are not" (italics in original) (Schiff, 1986, p.35).

This is the time to receive food, warmth and shelter and a nourishing diet of strokes that includes warm, intimate and pleasurable physical contact. Up to two months, especially if breastfeeding, primary symbiosis provides an intense bond between the mother and the baby, and a long separation between the baby and the caregiver responsible for feeding is not advisable.

If all this happens in a healthy way this symbiosis starts its way to resolve itself. However, this is not always the case.

With many infants, crying and nursing may not occur with satisfaction, as crying may cause irritation to the mother and breastfeeding may not be satisfactory, since the mother's tension will cause unsatisfactory and frustrating milk flow to the baby. The feeling of hunger, crying, hitting the arms - motility - may not be satisfied by breastfeeding, requiring from the baby an increase in the energy employed to be able to satisfy its need. There is, therefore, an increase in arrhythmic movements - Agitation without direction, without focus - generating what will later become one of the nonproductive types of passive behaviour, Agitation, according to Schiff.

In contrast, mother's overprotective behaviours by not allowing the baby to call for food with crying and arrhythmic movements can lead to passive behaviours of do nothing or Overadaptation.

Slow and mechanical breastfeeding, with few strokes, can also lead to the passive behaviour of Agitation.

The motility - unintended arrhythmic movements - of the baby should be stimulated and uninhibited yet infants may spend much of the time wrapped - our emphasis - in blankets or covers. This behaviour of preventing motility can establish the passive do nothing-behaviour in addition to sending Do Not Move, Do Not Act messages. This passive Do Nothing behaviour can trigger, at later stages, behaviours of shyness or withdrawal, or resemble depression, due the child's lack of movement-

\section{Advancing to the sensory-motor phase}

The baby enters the sensory-motor stage when it goes from motility to mobility - intentional movement. At this stage, the strokes come through a continuous supply of physical affection, and support permissions and qualification for action, curiosity, intuition. The formation of the Little Professor begins - A1.

With the pain caused by the eruption of teeth or the onset of colic, infants experience total helplessness and that of their caregivers, generating a phase of great frustration, as English (1977) emphasizes.

This moment is also one of great discoveries and the beginning of independence, for it is now that crawling and walking occur, the exploration of the environment, at the same time that vision, hearing and touch develops.

As Levin-Landheer (2010) observes, the incipient beginning of the resolution of primary symbiosis arises at this stage and needs to be viewed with tranquillity by the mother, and not as abandonment or loss of her baby who was so dependent and obedient -

At this stage begins the process of introducing solid nutrition with the subsequent weaning of the child.

The process of resolution of primary symbiosis may have its beginning or be prevented, depending on the events at this stage.

The baby begins to explore the world and the parents use methods to stop them moving and send messages of Don't Move, which can lead to passive Doing Nothing, Overadaptation and Agitation due to the restriction of locomotion and curiosity.

The mother, for fear of losing her little baby, does not start the weaning process and instead sends Do Not Grow messages, generating do nothing, Overadaptation and, often, Agitation, by preventing the search for food outside the mother's lap. It is important to emphasize that in the process of weaning the role of the father is important, requesting that the wife come back to being his spouse instead of being only mother.

The process of crawling and beginning to walk needs to be carried out with much support and protection. The baby has to hold the hand of the mother, the father or someone who gives security. Beginning to walk holding onto legs of chairs and furniture sends messages of unprotection, using a walker sends messages such as You are not Able, You will not succeed. These actions on the part of those who take care of the child can also induce, Doing Nothing, Overadaptation and, often, Agitation because the child 
feels restrained and unprotected. Insufficient surveillance of the small explorer can lead to conclusions of fear of new situations or a propensity to frequent accidents that generate strokes and later care. Such incapacitation or violence may lead in the future to the search for security in prison or in a psychiatric hospital, says English, (in Barnes, 1977).

\section{8 months to 3 years old}

Now the child enters the stage of independence, individuality and separation, "when the Adult ego state is first forming." (Levin-Landheer, 2010, p.187; original in English 1982, p.132).

Schiff (1986) comments that: "Curiosity emerges as a driving force, and children are hopeful, if not convinced, that when they complete their exploration of the universe they will have control over all things. The rapid learning which naturally happens at this time reinforces that expectation". (p.38)

Also the formation of $\mathrm{P} 1$ begins - the Parent in the Child - where begin to be recorded the messages of parenting that are now verbal. The injunctions begin to be recorded. Many of them impede the spontaneity and intimacy characteristic of the child's relationships with the world.

Berne (1988) observes: "A child's job is to find out what his parents really mean. This helps to maintain their love, or at least their protection, or in difficult cases, his mere survival". (p.92 - original in English 1972, p.101).

Now is the time for children to want space, to be different and unique. It becomes difficult for them to understand and control the world around them and to begin to understand that people have needs and feelings that are not necessarily the same. Now begin the years of rebellion where the "no" predominates. It is the 'terrible two's'. Children become angry, grumpy, and sometimes depressed as Schiff (1986) clarifies. According to English (in Barnes, 1977), the events of this phase will be repeated quite intensely in adolescence where real battles occur.

This incipient process of resolution of the primary symbiosis can be prevented by the parents through behaviours that stop the healthy social adaptation of the child to the conviviality of others. They may allow or encourage them to demonstrate their rebellion inappropriately or prevent them from perceiving the possibility of such separation in a protected manner.

The child now begins to learn to name the emotions and this is done by the parents or the caretaker. The child begins to perceive which feelings are approved and which are not, the latter being therefore dangerous to the obtaining of strokes. The child begins learning of the substitute emotions in counterpart to the authentic emotions that are perceived as forbidden. Don't Feel what you are feeling, Feel ... - this substitute emotion -, Don't Express what you are feeling. Don't Show what you feel or Act Uncontrollably.

Montheiro (2011) focuses on: "Since the emotion cannot be recognized and/or expressed it cannot motivate the social behavior linked to its satisfaction. As a substitute, the person may develop symptoms such as migraine, palpitation, nausea, for example (Erskine and Zalcman, 2006), which is the origin of psychosomatic problems, quite frequent in children with school difficulties such as headaches, nausea, vomiting, diarrhoea. Or, instead of the initial emotion, feel another. For example, by not being able to get in touch with her anger - which would motivate her to transform the situation that bothers her - the person becomes excessively "good" or overly agitated". (p.36)

As Montheiro clarifies, it is in the field of learning what emotional expression or performance is allowed or not, in the primary symbiosis, that some passive behaviour is established.

The do nothing behaviour that comes from the prohibition of expressing anger, for example, often leads to the substitute emotion of depression, for anger is intimately tied to the momentum of action toward what one wants to do. This can often be the cause of reactive depressions in very small children. Beginning to express or act upon the emotions that are allowed to you in a way to please parents will establish Overadaptation behaviour.

Substitute emotion, when expressed, does not allow the necessary discharge of the energy produced by the natural emotion and the quantum of energy that is retained can provoke the behaviour of Agitation and be a diagnostic factor in hyperactive children and with Attention Deficit Disorder - so common nowadays.

Passive behaviour can come from transforming the quantum of emotional energy retained into physical symptoms, enabling the child to partially discharge this unexpressed or liberated energy. Such a situation is often reinforced by intense stroking.

The injunction to act without control can lead to violence that, depending on the quantum of suppressed energy, causes the child to break household objects, toys, assault other children or even adults. It is the impossible children that no one can control - author's emphasises. These injunctions and emotion-related behaviours stem from the need for parents to keep their children in symbiosis, dependent on their care.

The child's natural rebellious behaviours and parents' inadequacy in dealing with them - whether repressing manipulatively - "You are bad!" or "Mom will no longer like/care for you if you continue like this" - or by encouraging by giving the child power she cannot have 
because she does not know what to do with it - "I do not know what to do with this boy, he's getting impossible!" or That's right, break everything and I'll clobber [hit] you!" - also lead to Do Not Do, Overadaptation, Agitation, incapacitation or violence that does not allow the symbiosis to dissolve.

\section{3 to 8 years - establishing an existential position and the primitive model of script}

During three to eight years, the child is now moving towards the structuring of the existential position, as English (in Barnes, 1977) puts it: “... I agree with Berne that between the ages of three and four the young child settles into an existential position which becomes the bedrock for his future script, because around that age he develops a need for a point of view for his relationships with others." (p.319).

She continues: "Children develop an "I'm not-Ok, You're OK" defensive position if, by age three, they have established a high proportion of conclusions related to helplessness and to being overpowered. In reverse, they will develop an "I'm OK, You're not-OK" defensive position if, so far, they have many conclusions about their power to "make" their caretakers feel good, or angry, or scared or guilty." ( $p$. 320).

From the structuring of these existential defensive positions is outlined which type of symbiosis will be established in adult life: if the individual structures the defensive position - / + they will seek complementary symbiosis with an individual who has structured the defensive position +/- and vice versa, developing the passive behaviour necessary to maintain this symbiosis.

It is also from three to eight years that the child structures the primitive script model. "We want to find out in a new way who we are and what it means to be the sex we are. We experience social relationships and become preoccupied with power", (LevinLandheer, 2010, p. 188 - original in English 1982, p. 132) At the end of this period, the development of the Parent ego state - P2 - is fundamental to the structuring of this primitive script model with all its apparatus - script payoff or curse, script Injunctions or stopper, provocation or 'come-on', pattern or program, impulses or demon, antiscript or internal release (Berne, 1988). Berne goes on to state that the anatomy of the script apparatus consists of the script controls - curse, stopper, and come-on - and the elements that can be used to counteract it - injunction, pattern, impulses, and antiscript.

Kertesz (1985), adds that the sequence of formation of this first script model begins with verbal and mainly non-verbal parent behaviours accompanied by strokes that are captured and analysed as messages by A1 based on the necessity of survival and consequently registered as injunctions in $\mathrm{P} 1$. Each recorded injunction will be linked to substitute emotions, existential position and concrete behaviours learned within psychological games. This first script protocol is being tried by testing behaviours that will be reinforced by the family with inappropriate strokes and any deviation from this pattern will be punished or ignored. At later ages the child will act this script outside the family, seeking partners who fit complementary roles.

Crema (1985), notes that the script is a routine, therefore without awareness, spontaneity and intimacy: "The description of the world, nurtured by the internal dialogues, conditions our habit of existing, which is the behavioral expression of the script. As a plan, at the structural and intrapsychic level, the script consists of the recording of mandates, injunctions and decisions of survival, which is expressed, phenomenologically, in the form of patterns of actions and habitual reactions. In other words, the script is an existential routine." (p. 209)

Script injunctions, according to Berne (1988), are the most important part of the script apparatus and can range from the most severe to the softest, all incorporated through blackmail or fear. The main ones are: Don't Live, Don't Enjoy, Don't Think, Don't Feel any emotion or a specific emotion - Don't Grow Up, Hurry to Grow Up, Don't Overcome Me, Don't Be Yourself Be Like ..., Don't Be Close, Don't Succeed, Don't Act, Don't Leave Me.

The injunctions related to not growing up and growing up fast are important in delineating the type of symbiosis that the individual will establish in the future. Those who received the injunction Don't Grow Up will seek to develop unresolved primary symbioses, and those who received the Grow Up fast injunction will develop secondary symbiosis.

We can infer that passive behaviours that maintain dependency relationships also serve elements of the script apparatus and play an important role in staying within the script.

Doing Nothing obeys some injunctions such as Don't Act, Don't Think, Don't Grow Up, Don't Overcome Me. Overadaptation also meets some injunctions - Don't Be You, Don't Overcome Me - and the script pattern or program and Agitation, Incapacitation and Violence relate to the provocation and the final script payoff.

In addition to the script injunctions, another important factor in this period of child growth are the attributes, that tell the child what to do or how to be. Steiner (1976), says that "Attributions when followed are reinforced, injunctions when disobeyed are punished." (p.67 - original in English 1975 p.74). 
Attributions can be of various types:

- You are a clown, laughing all the time; reinforces the injunction of Don't Enjoy;

- You are a fool, you don't make sense- reinforces the Injunction Don't Think;

- You are shy or You are withdrawn - reinforces Don't Approach;

- You are a sissy, you're a cry baby - reinforces Don't Feel;

- You are mommies baby - reinforces Don't Grow Up;

- You are the little man of the house, so responsible - reinforces Grow Up, Don't be a Child

- You are clumsy, you will never get where I am reinforces Don't Overcome or Don't Act, and many others.

An important attribution that reinforces the injunction Don't Be You, Be Like ... is the choice of the child's name.

A reminder - injunctions come from $\mathrm{P} 1$ of the parents and the attributions from $\mathrm{P} 2$.

These considerations, discussed above, refer to what happens up to the age of eight within the primary symbiosis, and thus create the boundaries of the degree and form of adaptation - by submission or rebellion - that the child will need to resort to in order to align with the reality that surrounds it. We emphasize that if the adaptation is by submission the predominant passive behaviour will be Do Nothing and Overadaptation with little energy discharge in the Agitation and Incapacitation or Violence conduits. If the adaptation is by rebellion, the predominant passive behaviour will be Agitation or Incapacitation or Violence with a lot of energy discharge instead of Do Nothing or Overadaptation behaviours. According to a Steiner (1976), "This process is a crucial point in the development of scripts and is called the decision." ... A script results from a decision that is both premature and enforced, because it is made under pressure and therefore long before a decision can be properly made." (p.74- original in English 1975 p.82-83). These decisions are made by Little Professor - A1 - with incomplete data, distorted reality and need for survival. These decisions will guide the individual, later, to seek the partners, in symbiotic relationships of dependence, to be able to keep his or her script.

\section{Adolescence}

From the age of eight until the end of adolescence, the basic premises of the script are already internalized, and it is time to start acting in social life. At this stage, the parenting process is influenced by other parent figures such as teachers, parents of friends, older teens, sports instructors, etc. The parenting occurring at home and now in society is forming the Parent ego state - P2 - as an autonomous ego state that will guide future decisions of behaviours; no longer from P1, by fear or gratification, but by a range of values and rules introjected in P2.

It is important to emphasize that in this phase the resolution of the primary symbiosis or its crystallization to guide future relationships will be finalized. The child and/or adolescent actively begins to exhibit behaviours of defiance or defence against the values of the parents. In response, acting to challenge authority may not be the best way, but neither is believing they can solve everything on their own. Conflict and confusion are typical of this time and the best way to deal with it is orientation, acceptance, dialogue and limits, so that the young person can succeed in resolving problems.

Levin-Landheer (2010), writes that "we periodically need to develop new tools, learn skills, and decide on values which are consistent with our goals. To do this we argue and hassle with others' morals and methods, often wanting to do things our own way and no one else's. " (p.199 - original in English 1982, p.133). Berne (1988), clarifies that "there are some people who rebel against their scripts, apparently doing the opposite of what they are "supposed" to. Common examples are the "rebellious" adolescent ..." (p. 117 original in English 1972, p.132).

During this period, concerns about sexuality begin to appear and adolescents begin their sexual experiences. In today's life, where appeals to sexuality come from all sides, having a conservative position based on fear will be highly problematic and will make it difficult to approach. Controlling or wanting to ignore are two opposites that need to be avoided.

We need to take into account that it is at this stage that the Parent-Adult-Child ego states of the individual are newly completed and that the lability of the cathexis is intense, because the membranes are not yet totally individualised and it is up to the parents, with guidance, empathy and protection, to help organize this cathexis. An Integrated Adult ego state of the parents will foster this integration in the children.

"Some parents are reluctant to experience the separation; others are glad to have successfully discharged their responsibility, and are eager to see the children as independent." (Schiff, 1986, p.46)

The primary symbiosis that would be mature - our emphasis - to be solved may not be so and analysing this non-resolution from the theoretical perspective of the miniscript of (Kahler and Capers, 2010), we can make some correlations with the passive behaviours of symbiosis. Timid children and adolescents, with little creativity, egocentric, with little volition, masking depressive behaviours, would be discounting 
themselves, which enables the start of the negative miniscript, with Do Nothing behaviour.

From miniscript position 1, failing to comply with the drivers of Please People, Hurry Up, Try Hard, Be Strong or Be Perfect, the person moves to Position 2, the Stopper or to Position 4, Final Payoff. The demeanour of quiet and well-behaved children and adolescents as they move through the miniscript, characteristic of the phase, would be Overadaptation.

Agitation and violence would be the behaviours in Position 3 of the miniscript, under the influence of the Vengeful Child, common in children and adolescents who are overly rebellious and destructive with antisocial behaviours. These behaviours would often come from acting in line with antiscript.

The very common Incapacitation behaviour of position 4 - I'm not OK, You're not OK - of the Final Payoff of the miniscript, would lead to frequent consultations with doctors and hospitals;

For good completion of the adolescence phase of development, and therefore the resolution of primary symbiosis, important messages are those such as: "'It's OK to learn how to do things your own way, to have your own morals and methods." "You don't have to suffer to get what you need." "You can do it your way." "You can think before you make that your way." "It's OK to disagree." "Trust your feelings to guide you."' (Levin-Landheer, 2010, p.190 - original in English 1982, p.134).

\section{Entering adult life}

Completing the cycle and entering fully into adulthood the personality is formed. Uncertainties and insecurities regarding the future are lived intensely. It is when they are looking for a new place in the world, to be successful is the goal, taking responsibility for their actions, being sexual, being who they are, and being able to count on their parental references.

Here is what Montheiro (2011) says: "Many events that have shaped or transformed our structure at the present time may not be useful, functioning as limitations. By eliminating these patterns, actualizing beliefs, dissolving tensions, amplifying the life force, gaining flexibility, internal expansion, and a new physical and emotional awareness." (p.39)

One is in search of a companion to connect to emotionally and to support the constitution of a family distinct from the original one, of social relationships and relationships of work. All these relationships may occur from a position of autonomy or a pathological symbiosis and dependence.

\section{Final considerations}

After this tour - our emphasis - we can make some reflections, trying to bring some of the references of these theorists to our therapeutic practice.

The whole structure of the human personality - ego states, the stroking system, emotional education, social structuring of time and the script, which will determine a framework - is built within a relationship of symbiosis that lasts no more and no less than eighteen years.

Each person will structure an affective relationship matrix to be employed in each relationship throughout life, whether loving a partner or in a family, social or professional context. Invitations to any relationship will interact with this matrix and seek to satisfy it.

The symbiosis is the scenario in which the script of each one unfolds, with the individual being the main character and the others the supporting players in the diverse relationships of dependence.

The therapist-client relationship will not escape this pattern and therapeutic symbiosis, which will be proposed later by the client, will need to be accepted as a manoeuvre and worked on to be resolved. The client will need to be led to the identification of which points in their development their primary symbiotic relationship has been maintained instead of being resolved, in order to be able to close the gestalts that have been formed.

We propose that in the therapeutic relationship, redefinitions, discounts, grandiosities and passive behaviours that justify, maintain and perpetuate the symbiotic relationship pattern, are worked out, so they can be solved, step by step, in a comforting and protective manner.

We propose to reflect on the possibility that this affective matrix of relationship, standardized back then, being resolved in a relationship, will be closed and will provide the rescue and liberation of autonomy and the possibility of relations in the here-and-now with awareness, spontaneity and intimacy.

Vitor A Merhy, MD, Psychiatrist is a Somatic Psychotherapist with specialisations in Reichian, developmental and transactional analysis psychotherapy. He is a Clinical Teaching Member of UNAT-BRASIL, of which he has been President 20172020. He is director of PsyAtiva, where he coordinates and manages training in Biopsychology. He can be contacted on vitoragra@terra.com.br 


\section{References}

Berne, Eric (1977) Os Jogos Da Vida. (Games People Play)

Rio De Janeiro: Artenova

Berne, Eric (1988) O Que Você Diz Depois De Dizer Olá? (What do you Say after you Say Hello) São Paulo: Nobel. [quotations taken from original version in English 1972, London: Corgi]

CREMA, Roberto. Análise Transacional Centrada Na Pessoa... E Mais Além. São Paulo: Ágora,1985.

Del casale, Franco. Ajuda-Me A Crescer. São Paulo: Summus, 1986.

English, Fanita .(1977) Beyond Script Analysis, In Barnes, Graham (Editor). Transactional Analysis After Eric Berne Teaching and Practices of Three TA Schools. New York: Harper's College Press

Kahler, Taibi \& Capers, Hedges (2010). O Miniscipt. Prêmios Eric Berne. Porto Alegre: União Nacional Dos Analistas Transacionais - UNAT-BRASIL
Kertesz, Roberto. (1985) Análisis Transacional Integrado. Buenos Aires: IPPEM

Levin-Landheer, Pamela. (2010) O Ciclo do

Desenvolvimento. Prêmios Eric Berne. Porto Alegre: União Nacional dos Analistas Transacionais - UNAT-BRASIL [quotations taken from original version in English LevinLandheer, Pam (1982) The Cycle of Development Transactional Analysis Journal 12:2 129-139]

Montheiro, Adriana (2011) Sinto, Penso no que sinto, logo existo. Um estudo sobre o significado das emoções e suas funções. Revista Brasileira de Análise Transacional, São Paulo, Vol XXI, Iss 1, 29-41

Schiff, Jacqui \& Contributors (1986). Leituras do Catexis Informal translation by Ralph Berg. Rio de Janeiro [quotations taken from original version in English 1986, Cathexis Reader New York: Harper \& Row]

Steiner, Claude. (1976) Os papéis que Vivemos na Vida. Rio de Janeiro: Artenova [quotations taken from original version in English 1986, Scripts People Live New York: Bantam Books] 